\title{
Intra-household exposure to labor market risk in the time of Covid-19: lessons from Mexico
}

\author{
Cecilia Peluffo ${ }^{1} \cdot$ Mariana Viollaz ${ }^{2}$
}

Received: 30 July 2020 / Accepted: 24 December 2020 / Published online: 29 January 2021

(c) The Author(s), under exclusive licence to Springer Science+Business Media, LLC part of Springer Nature 2021

\begin{abstract}
The ability to work from home can be critical during pandemics. We calculate an index that measures the possibility of working from home based on the characteristics of the pre-Covid-19 pandemic distribution of occupations and on internet access at home, using microdata for Mexico. Focusing on households with two partners employed in nonessential occupations, we show that there is high within-household correlation in the possibility of working remotely, which is likely to be positively associated with job stability during the pandemic. Poor families, with low access to formal credit and who rely heavily on informal mechanisms for consumption smoothing have lower chances of working remotely than richer families with higher access to formal credit. High within-household correlation in the workfrom-home index restricts the likelihood of intra-household risk-sharing and consumption smoothing, and is likely to contribute to an increase in inequality.
\end{abstract}

Keywords Intra-household exposure to labor market risk · Work from home · Inequality $\cdot$ Covid-19

JEL classification $\mathrm{D} 10 \cdot \mathrm{J} 22 \cdot \mathrm{O} 15$

\footnotetext{
An earlier version of this paper was circulated under the title "Intra-Household Insurance in the Time of Covid-19: Lessons from Mexico." We thank David Sappington and David Jaume for helpful comments and suggestions. Any remaining errors are our own.

Cecilia Peluffo

mpeluffo@ufl.edu

$\triangle$ Mariana Viollaz

mviollaz@cedlas.org

1 Department of Economics, University of Florida, 224 Matherly Hall, P.O. Box 117140, Gainesville, FL 32611-7140, USA

2 Centro de Estudios Distributivos, Laborales y Sociales (CEDLAS), IIE-FCE, Universidad Nacional de La Plata, La Plata, Argentina
} 


\section{Introduction}

Due to limited access to credit and formal insurance products, informal arrangements are important consumption-smoothing mechanisms for vulnerable populations in developing countries (Rosenzweig, 1988; Rosenzweig and Stark, 1989; Dercon, 2002; Angelucci and De Giorgi, 2009). A possible way in which families can mitigate the effects of individuals' negative earnings shocks on consumption are adjustments in spouses' labor supply. However, the Covid-19 crisis is likely to affect the scope for access to this intra-household mechanism. It has been shown that a pandemic recession imposes constraints on the use of intra-family adjustments in labor supply due to the increased childcare needs and because of the sectoral distribution of the shock and its differential impact on men and women (Alon et al., 2020b). Yet, little is known about intra-household correlation in exposure to labor market risk associated with pandemics like the Covid-19 pandemic. If the pandemic is characterized by labor market shocks that are positively correlated within a couple, spouses will face further restrictions in achieving consumption smoothing by adjusting their labor supply. ${ }^{1}$ We study this issue by examining within-household correlation in the possibility of working from home in Mexico.

Household members can make occupational choices with the objective of reducing the overall labor market risk the family faces (Doepke and Tertilt, 2016). We argue that even if spouses have made occupational choices in the past to minimize the household labor income volatility associated with regular recessions, the unique and unexpected features of the Covid-19 crisis are likely to affect the efficacy of such arrangements. One reason for this is that the types of tasks carried out on the job are gaining unprecedented relevance in determining exposure to the labor market shock during the pandemic. Occupations that involve tasks that cannot be performed remotely are being exposed to an increased labor market risk relative to occupations that can be performed from home. Intuitively, while in regular recessions the impacts on labor earnings tend to be linked to the sectors most affected by the downturn, in this recession the impacts are also mediated by the tasks performed at work. The overall effect of the pandemic on consumption will also be shaped by the distribution of the negative shocks across households with heterogeneous access to alternative sources of funds, such as savings, assets that can be liquidated, and other informal or formal insurance mechanisms or credit.

Mexico provides an interesting case to analyze due to the relevance of informal sources of insurance in the present crisis. Most countries in the Latin American region have introduced or extended social protection programs to provide income support to poor families and informal workers. Mexico is one of the countries providing less support in terms of GDP (World Bank, 2020). At the same time, more than half of the employed population are informal workers, so they do not benefit from labor protection mechanisms such as severance payment or unemployment insurance. With scarce support from public policies, households may rely heavily on intra-household arrangements or other informal risk sharing options.

\footnotetext{
1 Juhn and Potter (2007) argue that the value of marriage as a risk sharing mechanism can decline if the correlation between labor market shocks spouses receive increases.
} 
To shed light on this issue, we calculate a measure of the pre-pandemic amenability of working from home ( $W F H$ index hereafter) by combining data on tasks performed at work from the 2017 Mexican Survey of Adult Skills (PIAAC) and information from the 2018 National Survey of Household Income and Expenditure (ENIGH). The index is based on the characteristics of tasks performed on the job and on the availability of an internet connection at home and represents a measure of potential exposure to the Covid-19 shock in employment. It is built on influential work by Dingel and Neiman (2020) and follows a standardization procedure proposed by Acemoglu and Autor (2011). Our empirical approach has four main components, in which we (i) calculate the WFH index and show how it varies across households and individuals according to different demographic and employment characteristics, (ii) combine the WFH index with official registers of formal employment from the Mexican Institute of Social Security (IMSS) to provide evidence on the connection between aggregate changes in formal employment and the job amenability to working from home, (iii) calculate intra-household correlations of the WFH indexes of the spouses, and (iv) present evidence on the correlations between the WFH index and access to formal credit and informal consumption smoothing mechanisms at the household level.

Our analysis especially pertains to workers in nonessential sectors. Governmentmandated lockdowns around the globe have established which jobs or sectors are considered essential. Workers in these sectors are thus more likely than workers in nonessential sectors to continue to be employed, regardless of the types of tasks performed on their jobs. Because of this, we focus our analysis on cohabiting couples (regardless of their marital status) in which both partners are employed in nonessential occupations. ${ }^{2}$ This implies that the intra-household mechanism we study is based on ex ante occupational choices at the household level and ex post potential adjustments in the (intensive margin) labor supply of the partners.

We derive four primary findings. First, workers in the lower tail of the income distribution, informal workers, workers employed in small-size firms, and workers who do not own their homes tend to be employed in occupations with low WFH indexes. Second, employment in sectors in which workers have lower average WFH indexes is more likely to decline when social distancing policies are in place. Third, there is a high positive correlation between spouses' WFH indexes, which limits the scope for intra-household adjustments in labor supply to work as consumption smoothing mechanism during the pandemic. Fourth, households with low WFH indexes are less likely to have access to formal credit and more likely to rely on informal arrangements. Moreover, we document a positive correlation between spouses' average WFH index and the average WFH index of the municipality where each family lives, which we consider a proxy of their social network and potential source of informal insurance. Taken together, our findings imply that the pandemic is likely to exacerbate existing income inequalities.

This paper contributes to the general literature on intra-household risk sharing and assortative mating, which Doepke and Tertilt (2016) summarize. The paper also

\footnotetext{
2 The ensuing discussion employs the terms "married couples" and "couples" interchangeably. Similarly, we will employ the terms "spouse", "wife", "husband", and "partner" to denote cohabiting partners, independent of their marital status.
} 
contributes to the growing literature on the pandemic and its intra-household effects (e.g. Alon et al. (2020a), Alon et al. (2020b), and Heggeness (2020) for the U.S., Del Boca et al. (2020) for Italy, and Sevilla and Smith (2020) for the U.K.); the connection between telecommuting possibilities and employment changes during the pandemic (e.g., Beland et al. (2020) and Mongey et al. (2020) for the U.S., and Adams-Prassl et al. (2020) for Germany and the U.S.); and the association between WFH and economic vulnerability (e.g., Mongey et al. (2020) for the U.S., and Saltiel (2020) for a group of 10 developing countries).

To our knowledge, only three papers analyze couples' occupational sorting and its relationship to the possibility of working remotely. Lekfuangfu et al. (2020) identify a positive spousal correlation in job characteristics in Thailand. Malkov (2020) provides evidence of positive occupational sorting within couples in the U.S. We differ from these papers in that we rely on a WFH measure that incorporates the availability of an internet connection at home as a determinant. This factor has not been included by recent literature on WFH indexes for developed countries (e.g., Dingel and Neiman (2020); Mongey et al. (2020); Boeri et al. (2020)), but has been shown to be an important determinant of the feasibility of working remotely, especially in developing countries. ${ }^{3}$ In addition, we provide direct evidence on the relationship between the WFH index and employment and on the relationship between the WFH index and access to other sources of consumption smoothing. Finally, Alon et al. (2020b) construct a quantitative macroeconomic model for the U. S. to analyze how a pandemic recession impacts female and male employment, and how these effects are transmitted to aggregate demand, gender wage gaps, and social norms. Even though the authors do not present an analysis of within-household correlations of occupational characteristics, their model is calibrated considering the occupation types of spouses (can telecommute or not) to capture households' exposure to risk, highlighting the importance of the mechanism we examine.

The analysis proceeds as follows. Section 2 presents background information for Mexico. Section 3 describes the data. Section 4 describes household arrangements and employment indicators for individuals included in our analysis. Section 5.1 presents the WFH index and the pre-pandemic distribution of employment, and Section 5.2 presents estimates for the changes in formal employment based on the potential of telecommuting. Section 5.3 discusses the link between intra-household labor market risk and the Covid-19 pandemic, and Section 5.4 presents evidence on other formal and informal consumption-smoothing mechanisms. Section 6 concludes.

\section{Background}

We study the case of Mexico, a Latin American middle-income country in which almost $7 \%$ of the population lives on less than USD 3.20 a day (2011 PPP). In Mexico, as in many other developing countries, female labor force participation is

\footnotetext{
${ }^{3}$ Hatayama et al. (2020) and Garrote Sanchez et al. (2020b) include having an internet connection at home as part of the WFH index. Garrote Sanchez et al. (2020b) show that ignoring this factor leads to overestimating the feasibility of working remotely, and the bias is larger in less developed countries.
} 
low: Only $44 \%$ of women above 15 years old are active in the labor market, and men are 34.26 percentage points more likely to be active in the labor market than women. ${ }^{4}$ In developing countries, gender norms can act as a barrier to women's participation in the labor market (Jayachandran, 2020). Using information from the World Value Survey (Inglehart et al., 2014), Table 1 shows that in Mexico, $43.3 \%$ of respondents agree with the statement "If a woman earns more money than her husband, it's almost certain to cause problems"; $43.6 \%$ agree or strongly agree with the statement "When a mother works for pay, the children suffer." While other Latin American countries listed in the table (where the labor force participation of women is relatively low) show similar levels of agreement with these statements, the percentage of U.S. respondents who agree with the first and second statements are $12.4 \%$ and $24.8 \%$, respectively.

We examine how the ability to achieve consumption smoothing via intrahousehold adjustments in labor supply are affected by the pandemic. In the Mexican context, changes in spouses' labor supply can be rationalized by a model in which they make decisions on consumption and time allocation under social norms that affect female labor market choices by imposing costs on families (or individuals) who deviate from them. ${ }^{5}$ Social norms are likely to affect female labor market decisions, for example affecting the distribution of time spent providing childcare or other household chores by spouses. However, the existence of such norms does not necessarily preclude women from adjusting their labor supply when female work is one of the few options a household has in order to smooth consumption. ${ }^{6}$ Given that our indicator for exposure to labor market risk is based on characteristics of occupations, our sample is restricted to couples in which both spouses are employed (in nonessential jobs). Thus, we focus on the possibility of adjustments in the intensive margin of labor supply of one spouse as a response to the employment loss of his or her spouse. For example, in our sample of employed partners, that will be discussed in Section 3, we observe that women (on average) work less hours than men. If a husband losses his job during the pandemic, his wife could try to move from parttime to full time employment, or work overtime if she was already working full time. Likewise, the husband could try to increase his hours of employment if his wife becomes unemployed.

\footnotetext{
4 As a reference, in the U.S. this difference in favor of male participation is 12.06 percentage points. Source: World Development Indicators. Information for 2018 (poverty) and 2019 (labor force participation).

5 While our empirical analysis does not rely on imposing a specific intra-household decision model, gender norms affecting female labor market time allocation have been modeled following different approaches. For example, Alon et al. (2020b) assume (in the context of a model in which partners cooperatively decide on private consumption and labor supply) that households following traditional social norms suffer a utility loss (benefit) when the husband provides more (less) childcare than the wife does, when both spouses are employed. Alternatively, it is possible to assume that the time allocated to work outside the household by the wife can impose a utility cost on her husband (examples of this type of utility representation are provided by Fernández et al. (2004) and Basu (2006)).

${ }^{6}$ Examples of changes in wives' labor supply as a response to their husbands' transitions to unemployment in Mexico are provided by Parker and Skoufias (2004) and Skoufias and Parker (2006). Both papers find that the labor force participation of women whose spouses become unemployed significantly increases; Parker and Skoufias (2004) find that this effect is larger in recessions (when credit constraints may become more binding) than in periods of economic prosperity.
} 
Table 1 Gender norms

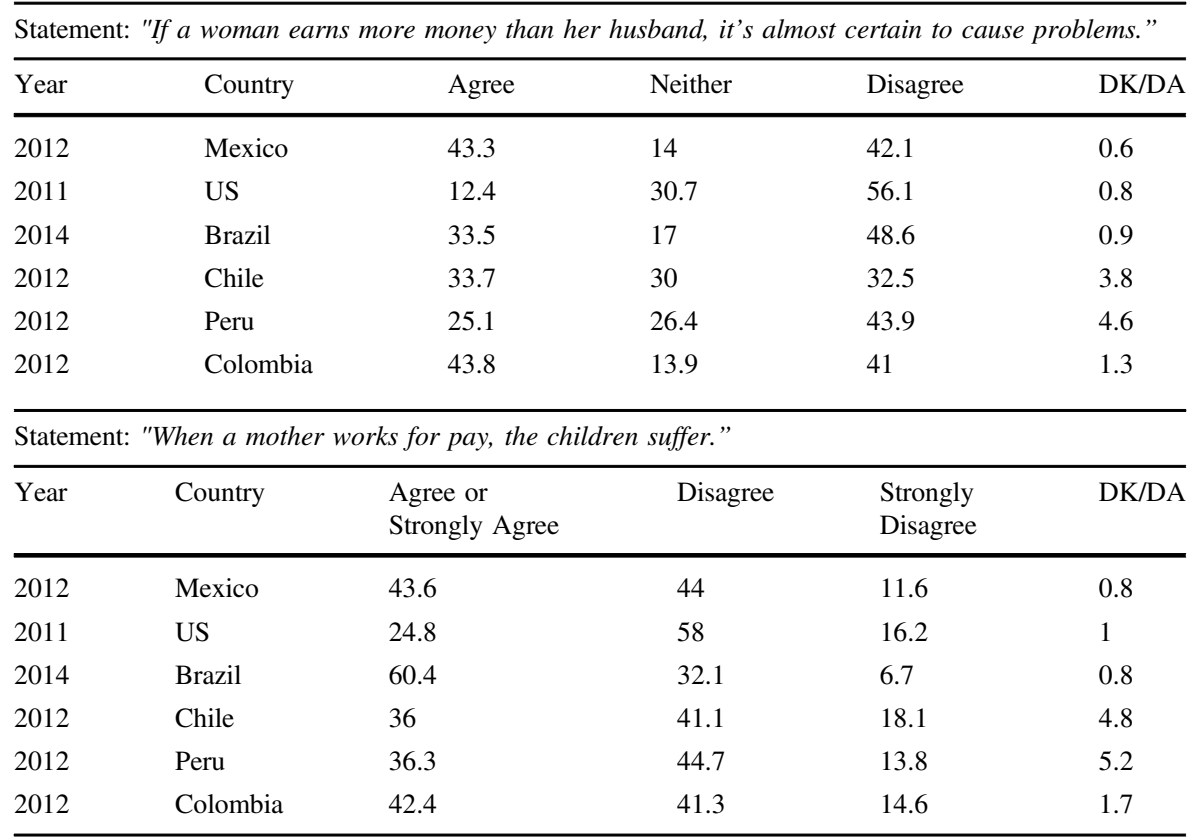

World Value Survey, Wave 6

Due to limited access to formal financial services (Bruhn and Love, 2014; Ambrosius and Cuecuecha, 2016), family-based informal insurance arrangements are particularly relevant in the Mexican context. Among these arrangements, evidence for Mexico indicates that families make use of remittances (Ambrosius and Cuecuecha, 2013), adjustments in the intra-household labor supply (Parker and Skoufias, 2004; Skoufias and Parker, 2006), and extended family networks (Angelucci et al., 2009). We believe that our analysis based on Mexican spouses who are both employed (in nonessential jobs) can help us understand patterns that are likely to be present in other developing countries where families rely heavily on informal mechanisms for consumption smoothing. These considerations are particularly relevant for poor households whose members are more likely to work in informal jobs, and typically do not have access to formal credit or savings.

\section{Data}

We use information from four data sources. First, we use the National Survey of Household Income and Expenditure (ENIGH) collected by the Mexican Institute of Statistics (INEGI) in 2018. The ENIGH is a nationally representative survey that collects information on households' income, expenses, demographics, and employment. Our analysis includes individuals between 15 and 60 years old. Our main variables of interest from the survey are occupation, sector of employment, 
access to an internet connection at home, and access to formal and informal credit or transfers. $^{7}$

Second, we use microdata from the 2017 Mexican Survey of Adult Skills (PIAAC), which is collected as part of the Programme for the International Assessment of Adult Competencies developed by the Organization for Economic Cooperation and Development (OECD). The PIAAC is a nationally representative survey that contains information on tasks performed at work for working-age individuals. We use a set of variables that capture the type of tasks respondents perform on their jobs. To calculate a WFH index, we combine the ENIGH and PIAAC surveys and match the information at the level of occupation (in Section 5.1 we describe the task-related variables and the construction of the WFH index in detail). ${ }^{8}$

Third, we use open-access data on formal employment from the Mexican Institute of Social Security (IMSS). Our analysis includes monthly information on total formal employment by economic sector, geographic area, and gender for individuals between 15 and 60 years old, for selected months in the period 2018-2020.

Finally, we use data from the Intercensal Survey of 2015, which is collected by INEGI and is representative at the municipality level. We use this survey to create a measure of the average WFH index in each municipality that we correlate with the average WFH index of spouses. To create the WFH index, we select the sample of employed men and women aged 15-60 and matched the WFH index generated using data from ENIGH and PIAAC (in Section 5.4 we describe the procedure applied to combine the information and create the index).

\section{Household arrangements and employment}

Table 2 shows the distribution of households in three alternative household arrangements: couples, female householder (households in which the household head is woman not cohabiting with a partner), and male householder (households in which the household head is a man not cohabiting with a partner). We observe that $69 \%$ of households are defined as couples (household head and spouse, with or without children). Of the couples, in $45 \%$ of the households only the man works, and in $51 \%$ both partners work. ${ }^{9}$

To mitigate the spread of the virus, several workplaces started closing during the last week of March 2020 (Hale et al., 2020). Restrictions continued until mid-June, when some sectors (in some states of the country) resumed activities while following protocols for social distancing. Sectors that continued operating - essential sectorswere defined by the national government in an official statement on March 31. Using these official guidelines, we identify essential workers in our data by combining information on sector of employment and occupation. We define as essential those workers employed in health, management of government social programs, electricity,

\footnotetext{
7 We include information on private transfers, donations, and remittances as informal sources of consumption smoothing. We use data on credit cards payments as a proxy for access to formal credit.

8 The PIAAC survey follows the International Standard Classification of Occupations 2008 (ISCO-08), while the ENIGH follows a national classification system (SINCO-2011). We use a correspondence table provided by INEGI to match data from PIAAC to the ENIGH at the 2-digit occupational level.
}

${ }^{9}$ We exclude 180 same-sex couples due to small-sample considerations. 
Table 2 Distribution of households by type and employment status

\begin{tabular}{llll}
\hline Household Type & Percentage & $\begin{array}{l}\text { Number of Households } \\
\text { in the Sample }\end{array}$ & $\begin{array}{l}\text { Number of Households } \\
\text { Represented }\end{array}$ \\
\hline $\begin{array}{l}\text { Panel A: Household Composition } \\
\text { Female householder }\end{array}$ & $21 \%$ & 10,850 & $5,332,724$ \\
Male householder & $10 \%$ & 5600 & $2,603,684$ \\
Couples & $69 \%$ & 38,544 & $17,714,889$ \\
Panel B: Couples by Employment Status & & \\
Only the man works & $45 \%$ & 17,570 & $7,911,424$ \\
Only the woman works & $2 \%$ & 899 & 437,658 \\
Neither works & $2 \%$ & 741 & 331,340 \\
Both partners work & $51 \%$ & 19,334 & $9,034,467$ \\
Panel C: Employed Couples by & Type of Employment & & $3,141,485$ \\
Both nonessential workers & $35 \%$ & 6302 & $2,636,824$ \\
Both essential & $29 \%$ & 5954 & $3,256,158$ \\
One essential & $36 \%$ & 7078 & \\
\hline
\end{tabular}

Authors' calculations using data from ENIGH 2018. Column 2 (Number of Households in the Sample) shows the number of observations by household type and employment status, while column 3 (Number of Households Represented) indicates the number of households represented in the sample, expanded using survey weights applied throughout the analysis. Female (Male) householder includes households in which the household head is a woman (man) not cohabiting with a partner.

gas and water supply, public administration and defense sectors, food preparation workers, employees of grocery stores and pharmacies, protective services workers, agricultural workers, manufacture of food and pharmaceutical products workers, workers in transportation and communication activities, and garbage collectors. In our 2018 data (ENIGH), in families with both spouses employed, both are classified as nonessential workers in $35 \%$, both are classified as essential workers in $29 \%$, and only one spouse is classified as an essential worker in $36 \%$.

To examine the effects of social distancing policies implemented during the Covid-19 crisis on the scope for consumption smoothing via intra-household adjustments in spouses' labor supply, the distinction between essential and nonessential workers is important. We will focus our analysis on the sample of families in which both the husband and wife are employed in nonessential jobs. Although not all workers in essential occupations will retain their jobs (for example, some grocery stores may be forced to reduce their staff due to the impact of the negative shock on the population's income, and consequently its effects on purchases), essential workers are more likely than nonessential workers to remain employed even if they cannot work remotely.

Table 3 contains descriptive statistics for families with partners who work in nonessential jobs distinguishing by their poverty status. The average age of women in the sample is 39 years, and the average age of men is 41 years. On average, both men and women have 11 years of education and $30 \%$ of the households have incomes below the poverty line. In terms of household composition, $4 \%$ of couples live with at least one person older than 60 , while in $59 \%$ of the households there is at least one child younger than 12 . Internet access at home is not widespread, with only $21 \%$ of 
Table 3 Descriptive statistics: couples in which both spouses are nonessential workers and all couples in Mexico

\begin{tabular}{|c|c|c|c|c|c|c|c|c|}
\hline & \multicolumn{2}{|c|}{ All sample } & \multicolumn{2}{|c|}{ Non-poor } & \multicolumn{2}{|l|}{ Poor } & \multicolumn{2}{|c|}{ All Mexico } \\
\hline & Women & Men & Women & Men & Women & Men & Women & Men \\
\hline \multicolumn{9}{|l|}{ Panel A: Demographic Indicators } \\
\hline Age & 38.89 & 41.27 & 39.40 & 41.71 & 37.69 & 40.25 & 39.32 & 42.05 \\
\hline Years of education & 11.26 & 11.16 & 11.96 & 11.78 & 9.65 & 9.73 & 9.54 & 9.66 \\
\hline Poor & 0.30 & 0.30 & 0.00 & 0.00 & 1.00 & 1.00 & 0.44 & 0.44 \\
\hline Presence of members older than 60 & 0.04 & 0.04 & 0.03 & 0.03 & 0.04 & 0.04 & 0.04 & 0.04 \\
\hline Presence of children younger than 12 & 0.59 & 0.59 & 0.53 & 0.53 & 0.74 & 0.74 & 0.65 & 0.65 \\
\hline Internet access at home & 0.36 & 0.36 & 0.43 & 0.43 & 0.21 & 0.21 & 0.24 & 0.24 \\
\hline \multicolumn{9}{|l|}{ Panel B: Labor Market Indicators } \\
\hline Wage employee & 0.76 & 0.79 & 0.80 & 0.80 & 0.69 & 0.75 & 0.62 & 0.77 \\
\hline Self-employed & 0.14 & 0.08 & 0.12 & 0.08 & 0.18 & 0.10 & 0.22 & 0.11 \\
\hline Weekly hours of work & 36.12 & 49.42 & 37.77 & 49.16 & 32.30 & 50.02 & 35.47 & 50.82 \\
\hline Hourly wage & 57.80 & 65.56 & 66.52 & 75.58 & 36.72 & 42.01 & 46.56 & 53.38 \\
\hline Formal employee & 0.44 & 0.52 & 0.51 & 0.57 & 0.26 & 0.38 & 0.41 & 0.44 \\
\hline \multicolumn{9}{|l|}{ Panel C: Occupations } \\
\hline Management Occupations & 0.06 & 0.09 & 0.08 & 0.11 & 0.02 & 0.05 & 0.04 & 0.05 \\
\hline Professionals and Technicians & 0.20 & 0.25 & 0.25 & 0.29 & 0.10 & 0.16 & 0.15 & 0.15 \\
\hline Clerical Support Workers & 0.08 & 0.04 & 0.09 & 0.04 & 0.04 & 0.04 & 0.07 & 0.03 \\
\hline Sales and Related Occupations & 0.19 & 0.10 & 0.18 & 0.10 & 0.21 & 0.10 & 0.18 & 0.09 \\
\hline Personal Services and Protective Service Workers & 0.07 & 0.03 & 0.07 & 0.03 & 0.08 & 0.03 & 0.10 & 0.07 \\
\hline Agricultural, Forestry, and Fishery Workers & 0.00 & 0.00 & 0.00 & 0.00 & 0.00 & 0.00 & 0.08 & 0.10 \\
\hline Craft and Related Trade Workers & 0.06 & 0.19 & 0.05 & 0.17 & 0.10 & 0.23 & 0.09 & 0.14 \\
\hline Plant and Machine Operators, Assembler, and Drivers & 0.08 & 0.12 & 0.09 & 0.12 & 0.07 & 0.13 & 0.04 & 0.16 \\
\hline Elementary Occupations & 0.25 & 0.16 & 0.20 & 0.12 & 0.38 & 0.25 & 0.26 & 0.22 \\
\hline \multicolumn{9}{|l|}{ Panel D: Sector of Employment } \\
\hline Agriculture & 0.005 & 0.011 & 0.004 & 0.012 & 0.005 & 0.011 & 0.111 & 0.170 \\
\hline Mining & 0.001 & 0.007 & 0.001 & 0.008 & 0.001 & 0.003 & 0.000 & 0.007 \\
\hline Manufacturing & 0.212 & 0.264 & 0.208 & 0.258 & 0.223 & 0.277 & 0.152 & 0.175 \\
\hline Construction & 0.014 & 0.198 & 0.017 & 0.174 & 0.006 & 0.252 & 0.007 & 0.146 \\
\hline Utilities & 0.000 & 0.000 & 0.000 & 0.000 & 0.000 & 0.000 & 0.001 & 0.006 \\
\hline Retail & 0.217 & 0.202 & 0.202 & 0.193 & 0.251 & 0.223 & 0.231 & 0.183 \\
\hline Transportation and Communication & 0.015 & 0.038 & 0.019 & 0.041 & 0.004 & 0.033 & 0.008 & 0.077 \\
\hline Services & 0.480 & 0.232 & 0.495 & 0.272 & 0.444 & 0.139 & 0.453 & 0.207 \\
\hline Social Services & 0.057 & 0.049 & 0.054 & 0.043 & 0.066 & 0.062 & 0.035 & 0.028 \\
\hline
\end{tabular}

Columns 1 to 6 contain averages for couples in which both spouses are nonessential workers, aged 15-60. Columns 7 and 8 show averages for all couples, aged 15-60, regardless of spouses' employment status. Hourly wage is in Mexican pesos. Formal employee only includes wage employees with contributions to the social security system. Poverty status is defined using the poverty line reported by the National Council for the Evaluation of Social Development Policy (CONEVAL) for the period in which the ENIGH was implemented (September-November, 2018). The urban poverty line is 3036.3 Mexican pesos and the rural poverty line is 1964.1 Mexican pesos. Authors' calculations based on ENIGH 2018

poor households and $43 \%$ of non-poor households having access to an internet connection at home. Self-employment and informal wage employment are more common in women and poor families, with $14 \%$ of women and $8 \%$ of men being selfemployed and $44 \%$ of women and $52 \%$ of men working in registered jobs. On average, women work fewer hours per week (36 hours) than men (49 hours) and earn 
a lower hourly wage. In terms of occupation, there is substantial variation across gender and poverty status. Women are strongly concentrated in elementary occupations (such as domestic service), professional and technician occupations, and retailing (64\% of total employment), while men mainly work as professionals or technicians, in elementary occupations (for example, as building construction laborers), or in craft and related occupations (60\% of total employment). This variation across genders and the differential access to an internet connection at home by poverty status will be important in identifying the possibility of working from home. The last panel of Table 3 displays the sectoral distribution of employment in the sample, and shows that $48 \%$ of women work in services, followed by $22 \%$ in retail. For men, $26 \%$ work in manufacturing, followed by $23 \%$ in services.

Finally, in the last two columns of Table 3, we report demographic and employment characteristics for all couples in the country (independently of the partners' employment status) in the same age group as our sample of partners who work in nonessential jobs. Comparing individuals in our sample with the average couple in the country, we observe that women and men in the sample are slightly younger, more educated, less likely to have children, more likely to have access to the internet, and less likely to be poor than the overall population (differences that are consistent with having selected a sample of employed couples). Among employed individuals, we observe a similar employment distribution by occupation and sector for each gender when comparing our sample and all couples in Mexico. Individuals in our sample are less likely to be self-employed and more likely to be wage employees than the average partners in Mexico.

\section{Findings}

\subsection{WFH index and pre-pandemic distribution of employment}

The extensive implementation of remote work arrangements due to social distancing and lockdown policies have led to a rapidly growing literature on how to measure a job's amenability to working from home. Most studies rely on measures of the types of tasks performed in different occupations in the U.S. economy (Dingel and Neiman (2020), and several papers that apply this measure to the U.S. and other countries). ${ }^{10}$ As in Hatayama et al. (2020), we calculate a WFH index that differs from the influential measure introduced by Dingel and Neiman (2020) in three important respects. First, instead of calculating the share of jobs that can be performed at home within each occupation, we calculate an index of jobs' amenability to remote work. ${ }^{11}$

\footnotetext{
${ }^{10}$ Examples include Gottlieb et al. (2020a), Lekfuangfu et al. (2020), Delaporte and Peña (2020), Beland et al. (2020), Garrote Sanchez et al. (2020a).

11 Dingel and Neiman (2020) consider that a job is not suitable for remote work when at least one of various conditions holds, e.g., operating mechanized devices is very important, working directly with the public is very important, among others. During the pandemic, the use of ICT can allow, for some occupations, to carry out some activities, such as those involving face-to-face interaction. A job that the Dingel and Neiman's (2020) criterion classifies as not amenable to work-from-home, could have a high WFH index in the methodology we follow when the interaction between face-to-face tasks and ICT tasks is considered.
} 
Second, we use Mexican data on tasks performed at work rather than relying on a U. S.-based measure to draw conclusions for a developing country. ${ }^{12}$ Third, we include internet access at home as a determinant of WFH possibilities. Workers in developing countries may use Information and Communications Technology (ICT) at work and have internet access at their workplace, but may not have an internet connection at home. Given this fact, it has been shown (Garrote Sanchez et al., 2020b) that not taking into account the internet at home component when calculating WFH indexes can result in an overestimation of the feasibility of working remotely, particularly in developing countries.

For the ENIGH sample of employed men and women, we generate the WFH index by combining task variables in occupations (from PIAAC) with a variable that indicates access to an internet connection at home. In the PIAAC database, we identify a set of work-related task variables and group them in three categories: physical and manual tasks, ICT tasks, and face-to-face tasks. ${ }^{13}$ Table 4 lists the variables included in each task-category. Variables related to physical and manual work consider activities that are more likely to require being at a specific site, e.g., activities that use specific equipment and cannot be done at home. ICT captures tasks, such as the use of computers and the internet, that we expect to be more amenable to remote work. Face-to-face variables are those that involve personal interaction, such as contact with coworkers or the general public. These tasks are, in principle, not amenable to working from home, but they could be performed remotely when mediated by ICT technology.

We apply the standardization procedure proposed by Acemoglu and Autor (2011) and applied in Hatayama et al. (2020) and other studies that analyze tasks performed at work (i.e., Lewandowski et al. (2019), Almeida et al. (2020)). We proceed by first calculating, in the PIAAC database, the average value of each task variable at the 2-digit occupational level for men and women separately. ${ }^{14} \mathrm{We}$ aggregate the data from the individual to the occupational level in order to match the task-related information to the ENIGH. We do that by using the correspondence between the classification of occupations in PIAAC (ISCO-08) and the national classification system followed by ENIGH (SINCO-11). Next, using the ENIGH sample of employed men and women, we standardize each task variable and the internet connection at home variable. We add across all variables within each task group (defined in Table 4) and normalize each sum to have mean zero and variance one. The WFH index is obtained by adding the three normalized task group measures and the normalized internet connection at home variable, and

\footnotetext{
${ }^{12}$ Gottlieb et al. (2020b) compare, for ten developing countries, a WFH measure obtained by applying the U.S.-based measure of Dingel and Neiman (2020) at the occupational level with a WFH measure obtained by applying Dingel and Neiman's (2020) methodology to country-specific data. Their results show differences in the share of jobs that can be performed from home within each occupation that range between 5 to 31 percentage points.

13 Our sample includes 4,237 observations. We use all the sample, without imposing restrictions on age (PIAAC reports information for employed individuals between 16 and 65 years old).

14 In the case of physical and manual task variables and face-to-face interaction variables, we reverse the value of the categories such that a higher value implies that the job is more suited to working from home. See Table 4 for more details.
} 
Table 4 Variables about tasks performed at work

Physical \& Manual Index

Frequency of working physically for a long period

Frequency of using skill or accuracy with hands or fingers

Face-to-Face Index

Frequency of sharing work-related information with co-workers

Frequency of instructing, training or teaching people, individually or in groups

Frequency of making speeches or giving presentations in front of five or more people

Frequency of selling a product or selling a service

Frequency of advising people

Frequency of persuading or influencing people

Frequency of negotiating with people either inside or outside the firm or organization

ICT Index

Frequency of using email

Frequency of using the internet in order to better understand issues related to the work

Frequency of conducting transactions on the internet, for example buying or selling products or services, or banking

Frequency of using spreadsheet software, for example Excel

Frequency of using a word processor, for example Word

Frequency of using a programming language to program or write computer code

Frequency of participating in real-time discussions on the internet, for example online conferences, or chat groups

Each variable ranges from 1 (never) to 5 (every day). In the case of physical and manual task variables and face-to-face interaction variables, we reverse the value of the categories such that a higher value implies that the job is more suited to working from home. PIAAC (2017)

normalizing one more time. ${ }^{15}$ The resulting index has mean zero and variance one for the entire sample of employed men and women. A higher value of the index indicates higher amenability to work from home.

Considering households in which both spouses work in nonessential jobs, in Table 5 we show the average WFH indexes for different groups of individuals and the average of the standardized task categories and internet connection at home for men and women. The first observation is that women have a larger average WFH index than men. This is explained by a higher female participation in occupations that involve less physical and manual work and require less face-to-face interaction. Even when the use of ICT at work is more prevalent for men, the contribution of this factor to the WFH index is not enough to compensate for the large differences based on physical work and face-to-face interaction observed in employment between genders. Conditioning on gender, individuals who live in households with incomes below the poverty line, individuals who do not own their home, workers in small firms, and workers in the informal economy tend to be employed in jobs with lower possibilities of telecommuting. Our main analysis will focus on households in which

\footnotetext{
${ }^{15}$ Each normalized task variable receives equal weight when adding them within each task group. Similarly, each normalized task group measure and the normalized internet connection at home variable receive equal weight when we add them to obtain the WFH index.
} 
Table 5 WFH index of women and men in couples by employment status

\begin{tabular}{|c|c|c|c|c|c|}
\hline & \multicolumn{2}{|c|}{ Both nonessential } & \multirow{2}{*}{$\begin{array}{l}\text { Women } \\
\text { essential } \\
\text { WFH Men }\end{array}$} & \multirow{2}{*}{$\begin{array}{l}\text { Men essential } \\
\text { WFH Women }\end{array}$} & \multirow{2}{*}{$\begin{array}{l}\text { Women not } \\
\text { employed } \\
\text { WFH Men }\end{array}$} \\
\hline & WFH Women & WFH Men & & & \\
\hline All & 0.74 & -0.03 & -0.29 & 0.59 & -0.29 \\
\hline Poor & 0.42 & -0.40 & -0.51 & 0.40 & -0.54 \\
\hline Non-poor & 0.87 & 0.13 & -0.17 & 0.69 & -0.05 \\
\hline Own home & 0.84 & 0.06 & -0.29 & 0.70 & -0.25 \\
\hline Doesn't own home & 0.55 & -0.16 & -0.32 & 0.64 & -0.35 \\
\hline Small firm & 0.52 & -0.38 & -0.51 & 0.46 & -0.52 \\
\hline Large firm & 1.00 & 0.23 & -0.11 & 0.82 & -0.13 \\
\hline Formal workers & 1.08 & 0.33 & 0.06 & 0.95 & 0.03 \\
\hline Informal workers & 0.61 & -0.33 & -0.54 & 0.53 & -0.53 \\
\hline Physical \& manual (reverse) & 0.93 & -0.24 & -0.47 & 0.90 & -0.45 \\
\hline ICT at work & 0.25 & 0.37 & 0.08 & 0.08 & 0.13 \\
\hline Face-to-face (reverse) & -0.06 & -0.45 & -0.17 & 0.08 & -0.22 \\
\hline Internet access at home & 0.27 & 0.27 & 0.01 & 0.07 & -0.01 \\
\hline
\end{tabular}

Authors' calculations using data from ENIGH (2018) and PIAAC (2017)

both spouses are nonessential workers. However, we observe that the same patterns are found in households in which one partner is an essential worker (in that case, we only report the WFH index for the nonessential worker) and in households in which only the husband works (in a nonessential job).

To explore the connection between the WFH index and changes in employment levels, we rely on official information from the Mexican Institute of Social Insurance (IMSS) on the number of formal employees by sector, region, gender, and month. Given the high prevalence of informality in the Mexican labor market, information on formal employment is not representative of overall changes in employment. Moreover, due to labor regulations, we expect formal employment to be more protected than informal employment in the event of a negative shock. In the absence of alternative data sources on overall employment that can be compared with previous employment figures, ${ }^{16}$ we rely on formal employment data to provide evidence on the link between the WFH index and changes in employment. Table 6 shows the distribution of formal employment across sectors and genders for March 2019 (1 year before social distancing restrictions were implemented). Formal employment is largely concentrated in services, manufacturing, and retail. In terms of gender composition, social services (health, education, and personal services) is the only sector with more than $50 \%$ of female workers.

\footnotetext{
${ }^{16}$ Mexico collects monthly information on labor-related variables through the Encuesta Nacional de Ocupación y Empleo (ENOE). In April, the survey started to be collected by phone, which changed the sampling design and sample size. We follow the advice provided by INEGI and do not compare pre-Covid19 data (March 2020 and before, when the ENOE was collected) with data collected during the pandemic (April and May, when the phone survey was conducted).
} 
Table 6 Formal employment by sector

\begin{tabular}{lllccc}
\hline Sector & Women & Men & $\begin{array}{c}\text { \% of Female } \\
\text { Employment }\end{array}$ & $\begin{array}{c}\text { \% of Male } \\
\text { Employment }\end{array}$ & Share Female \\
\hline Agriculture & 184,157 & 546,548 & 2.46 & 4.46 & 0.25 \\
Mining & 11,978 & 114,267 & 0.16 & 0.93 & 0.09 \\
Manufacturing & $1,991,674$ & $3,451,466$ & 26.65 & 28.19 & 0.37 \\
Construction & 234,836 & $1,335,431$ & 3.14 & 10.91 & 0.15 \\
Utilities & 31,104 & 110,634 & 0.42 & 0.90 & 0.22 \\
Retail & $1,597,781$ & $2,323,140$ & 21.38 & 18.98 & 0.41 \\
Transportation \& & 242,124 & 891,781 & 3.24 & 7.28 & 0.21 \\
Communication & & & & & 0.43 \\
Services & $1,980,442$ & $2,608,417$ & 26.50 & 21.31 & 0.58 \\
Social Services & $1,199,129$ & 860,437 & 16.05 & 7.03 & \\
Total & $7,473,225$ & $12,242,121$ & 100 & 100 & \\
\hline
\end{tabular}

Data for March 2019. Individuals between 15 and 60 years old. Authors' calculations using data from IMSS, Mexico

\subsection{WFH and changes in employment during the Covid-19 pandemic}

We rely on information on formal employment to study the association between amenability to working from home (measured by the WFH index calculated using the pre-pandemic distribution of occupations) and sectoral changes in employment during the pandemic. In Fig. 1, each dot (in each plot) represents the inter-annual change in formal employment for a given sector of activity, gender, and month (April or May). The panel on the left contains information on changes in registered employment between 2018 and 2019 (before the pandemic) and the panel on the right shows changes in employment between 2019 and 2020 (during the pandemic). Each plot contains 36 dots, representing specific month, gender, and sector combinations $(2 \times 2 \times 9) .{ }^{17}$ The horizontal axis in each plot shows the average WFH index for individuals working in formal jobs for each gender and sector combination for the period $2018 .{ }^{18}$ In the period 2018-2019, we do not find a systematic relationship between the average WFH index in each sector and gender combination and inter-annual changes in employment for April and May (Fig. 1, left panel). However, 1 year later (during the pandemic period), we find a positive relationship between the WFH index and inter-annual changes in employment (Fig. 1, right panel). This pattern indicates that jobs with a lower scope for remote work (according to the pre-pandemic distribution of tasks and internet access for those employed in them) were particularly affected during the Covid-19 crisis.

\footnotetext{
17 We use the same nine sectors included in Table 6.

18 Given that the data on registered workers (from IMSS) do not contain information on household composition of workers, the analysis includes all registered workers between 15 years and 60 years regardless of whether they live with a partner or not. WFH averages are calculated using data from the sample of employed men and women who have formal jobs in the ENIGH (we identify workers in formal jobs as wage employees contributing to the social security system) and information on tasks from PIAAC. Given the level of aggregation of the formal employment data we are using, in this section we do not distinguish between essential and nonessential workers.
} 

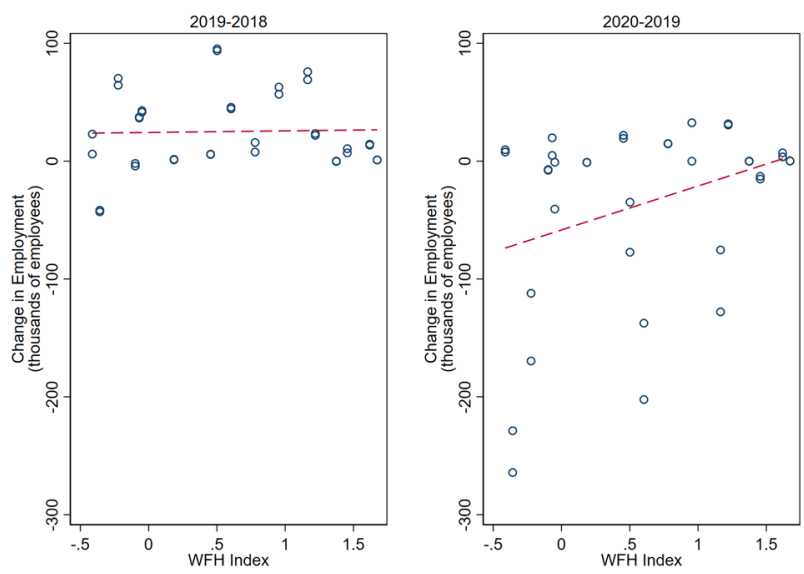

Fig. 1 Inter-annual variation in formal employment (by month) and WFH index (2019-2018 and 2020-2019). Each dot in the plot represents the inter-annual change in formal employment (in thousands of employees) between 2018 and 2019 (on the left panel) or between 2019 and 2020 (on the right panel), for April and May, for a given sector of activity, gender, and month. The horizontal axis shows the average WFH index for individuals working in formal employment for each gender and sector combination. Authors' calculations based on data from IMSS (2018-2020), ENIGH (2018), and PIAAC (2017)

To explore the association between WFH indexes and inter-annual changes in (formal) employment levels at different points in time, we estimate models using information for 2018-2020 and for April and May in each year. We consider the following baseline specification:

$$
L_{s r g t}=\alpha+\sum_{t=0}^{T} \beta_{t} W F H_{s r g} \cdot \gamma_{t}+\gamma_{t}+\epsilon_{s r g t},
$$

where $L_{\text {srgt }}$ is the inter-annual change in employment in sector $s$, region $r$, and gender $g$ between month-year $t$ and the monthly level of employment reported 12 months before (where $t=$ April 2019, May 2019, April 2020, and May 2020); $W F H_{s r g}$ is the average WFH index for sector $s$, region $r$, and gender $g$ (calculated using data from ENIGH for 2018 and PIAAC for 2017); $\gamma_{t}$ are fixed effects by month-year; and $\epsilon_{s r g t}$ is an error term.

The estimated results, presented in Table 7, convey the same patterns as the aggregate changes in Fig. 1. The estimated coefficients in the baseline model indicate that, after controlling for common shocks by period, the WFH index is not significantly associated with inter-annual changes in formal employment in April and May between 2018 and 2019. However, in the Covid-19 crisis period, having a one standard deviation smaller WFH index is correlated with an employment loss of 3.14 (3.79) thousand formal jobs in April (May) 2020 with respect to the same month in 2019. These magnitudes represent formal employment reductions of $2.24 \%$ and $2.71 \%$ with the respect to the average employment level in April and May of 2019, respectively. The direction of the result is robust to different specifications: Model (1) contains the baseline regression that controls for fixed effects by month-year to account for common shocks in each period; Model (2) adds fixed effects by sector of activity to the baseline model, to control for time-invariant unobserved characteristics at the sector of activity level; Model (3) adds fixed effects by region, to control for 
Table 7 Inter-annual variation in formal employment (by month) and WFH index (2018-2020)

\begin{tabular}{llllll}
\hline & Model (1) & Model (2) & Model (3) & Model (4) & Model (5) \\
\hline wfhxApril2019 & 0.185 & 0.693 & 1.011 & -0.513 & -0.695 \\
& $(0.685)$ & $(0.779)$ & $(0.822)$ & $(1.108)$ & $(1.122)$ \\
wfhxMay2019 & 0.602 & 1.109 & 1.428 & -0.096 & -0.279 \\
& $(0.733)$ & $(0.828)$ & $(0.868)$ & $(1.108)$ & $(1.126)$ \\
wfhxApril2020 & $3.136 * * *$ & $3.643 * * *$ & $3.962 * * *$ & $2.438 *$ & $2.256^{*}$ \\
\multirow{2}{*}{ wfhxMay2020 } & $(1.150)$ & $(1.021)$ & $(1.051)$ & $(1.348)$ & $(1.334)$ \\
& $3.789 * * *$ & $4.297 * * *$ & $4.616 * * *$ & $3.092 * *$ & $2.909 * *$ \\
$N$ & $(1.422)$ & $(1.271)$ & $(1.282)$ & $(1.467)$ & $(1.457)$ \\
\hline
\end{tabular}

Dependent variable: change in employment (in thousands) relative to the same month in the previous year. Model (1) includes fixed effects by month-year; Model (2) includes fixed effects by sector of activity and fixed effects by month-year; Model (3) includes fixed effects by region, fixed effects by sector of activity, and fixed effects by month-year; Model (4) includes fixed effects by region, fixed effects by sector of activity, fixed effects by month-year, and fixed effects by gender; Model (5) includes fixed effects by region, fixed effects by sector of activity, fixed effects by month-year, and fixed effects by gender, and controls for level of employment in March 2018. Robust standard errors are reported in parenthesis. Authors' calculations using data from IMSS (2018, 2019, and 2020), ENIGH (2018), and PIAAC (2017)

time-invariant unobserved characteristics at the regional level; Model (4) adds fixed effects by gender; and Model (5) adds the level of employment in March 2018, to control for the initial size of each cell (defined at the sector-region-gender level).

\subsection{The Covid-19 pandemic and intra-household labor market risk}

After defining the WFH index and examining the potential connection between this measure of the possibility of telecommuting and employment, we proceed to present evidence on within-household correlation of spouses' WFH indexes. As previously discussed, intra-household consumption smoothing is typically achieved by (intensive and extensive margin) increases in the earnings of one spouse as a response to the loss in earnings of the other spouse. In this paper, we study potential restrictions to the intensive margin mechanism based on the intra-household correlation in exposure to the shock.

We focus on spouses employed in nonessential occupations. If the within-couple WFH index correlation is positive, when one spouse is employed in an occupation with low amenability to remote work, the other spouse is likely to be employed in an occupation in which the possibility of telecommuting is also low. In this case, the severity of the negative shock of the pandemic on employment is likely to be positively correlated for spouses, amplifying the potential negative effects of the shocks for individuals who are particularly affected due to the impossibility of working remotely. Alternatively, if there is a negative correlation in the WFH index between spouses, the probability that both spouses will lose their jobs will be lower. Moreover, in this context, the spouse who has the possibility of telecommuting could adjust his or her labor supply to compensate for the loss of employment of the partner who might not be able to work remotely. 
All figures in this section are binned scatter plots, with 100 equal-sized bins for the WFH index of the husband (x-axis variable). Each figure shows a scatter plot for the data points that represent the mean of the WFH index of the husband and the mean of the WFH index of the wife (y-axis variable) within each bin. The plots also contain the best linear fit line (OLS regression) for the relationship between the WFH index of the spouses. Figure 2A provides a graphic representation of the relationship between the WFH index of the husband and the WFH index of the wife using the sample of families in which both partners are employed in nonessential jobs. The linear regression shows that, on average, when the husband has a job that is more amenable to working from home, the wife is also more able to telecommute. Specifically, for each standard deviation increase in the husband's WFH index, we observe an average increase in the wife's WFH index of 0.56 standard deviations (the coefficient is statistically significant).

The possibility of working from home may be affected by access to the internet at home. In our sample, $36 \%$ of households had an internet connection at home in 2018, and internet access was more than twice as likely in non-poor than in poor households (Table 3). Given that our sample includes spouses who share their place of residence, the positive correlation of their WFH indexes will be, in part, explained by this factor. To examine how much of the intra-household correlation is explained by features of the respective occupations, we construct a new index that is based only on the characteristics of the tasks performed on the job. In Fig. 2B, we estimate the correlation between the indexes of the spouses for this adjusted version that nets out the effect of internet access at home. We observe that the correlation between the indexes remains positive. The result indicates that a one-standard-deviation increase in the occupation-based WFH index of the husband is associated (on average) with a 0.18-standard-deviation (statistically significant) increase in the occupation-based WFH index of the wife. The smaller correlation between spouses' WFH indexes when excluding internet access at home is suggestive of the importance of considering this infrastructure determinant of workfrom-home possibilities for estimating the degree of intra-household correlation in exposure to labor market risk during the pandemic.

In Fig. 2C, we exclude households in which the spouses work in the same economic sector. Even when spouses work in different economic sectors (which may receive different demand shocks during the pandemic), their exposure to labor market risk exhibits a positive correlation based on their WFH indexes (the coefficient is 0.51 and statistically significant). Similarly, positive assortative mating by education can play a role in explaining the intra-household correlation in the WFH index due to the potential connection between formal education and the abilities required to perform job tasks that can be carried out at home. To test whether the results are due to assortative mating in terms of education, Fig. 2E excludes couples in which both partners have the same educational level. The results are robust to this exclusion, with a (statistically significant) estimated coefficient of 0.52 .

The results in panels (C) and (E) imply that the positive correlation of partners' exposure to labor market risks during the pandemic (proxied by the possibilities of WFH) goes beyond a correlation that is due to assortative mating (in terms of education or sector of employment). During the pandemic the types of tasks carried out on the job gained unprecedented relevance in determining exposure to the labor market shock. These tasks, however, are not necessarily sector specific or tied to a particular level of formal education. We find that households exhibit a positive 

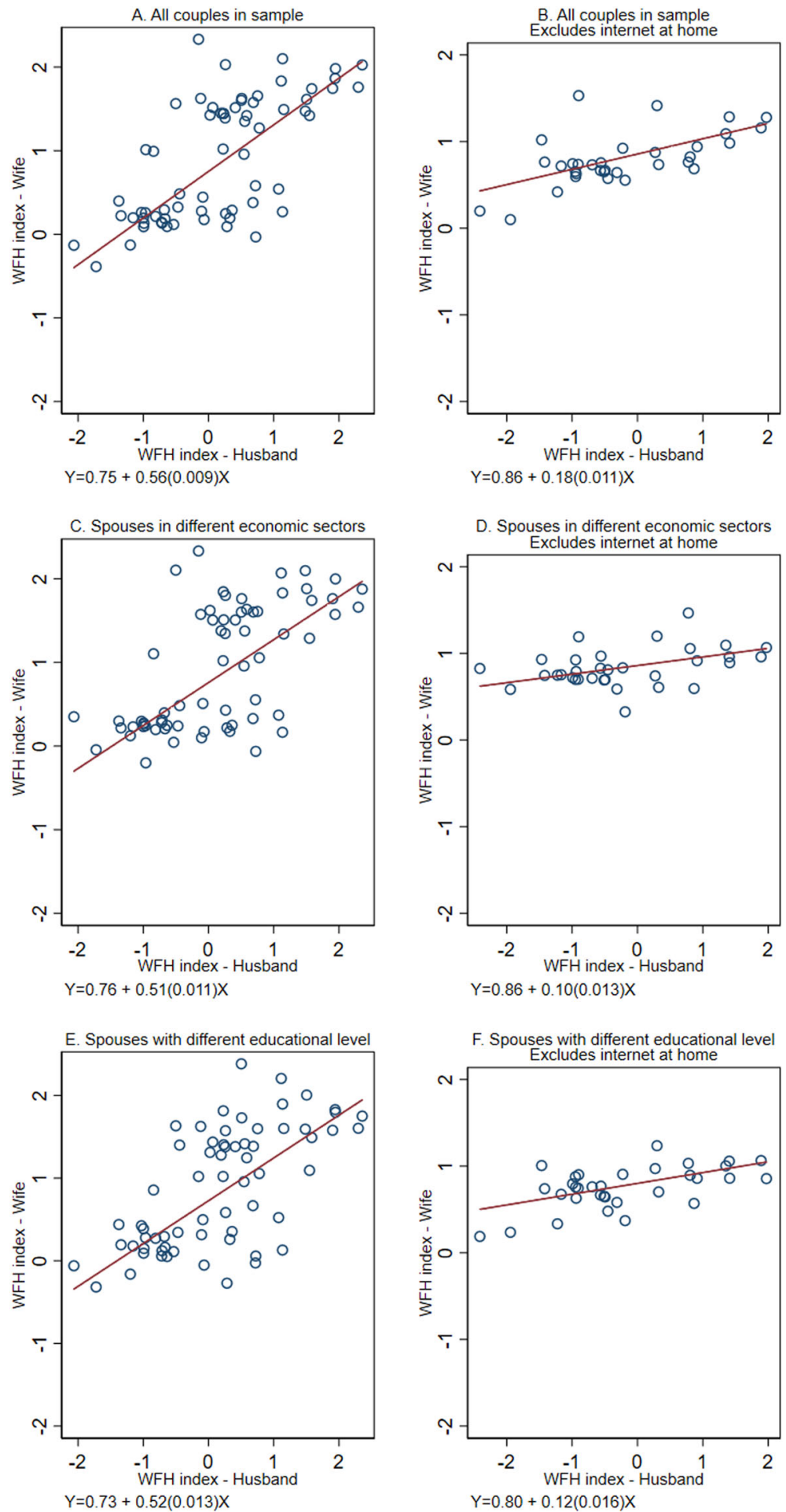
Fig. 2 Correlation between spouses' WFH indexes. Couples in which both spouses are employed in nonessential jobs. A, C, and $\mathbf{E}$ contain the WFH indexes for the complete sample, for the sample that excludes spouses in the same economic sector, and for the sample that excludes spouses with the same level of education, respectively. $\mathbf{B}, \mathbf{D}$, and $\mathbf{F}$ replicate figures in $\mathbf{A}, \mathbf{C}$, and $\mathbf{E}$, respectively, using a modified index that excludes the internet at home component. The minimum and maximum values of the WFH index across panels are -1.07 and 3.24 for wives and -2.41 and 2.36 for husbands, respectively. Authors' calculations based on data from ENIGH (2018) and PIAAC (2017)

correlation in exposure even if the members have different educational levels or work in different sectors. A potential explanation for this result is the existence of unobserved factors such as family background, tasks learned at home, or joint labor market experience, that explain a positive correlation of the types of tasks spouses perform on their jobs. Finally, panels (D) and (F) of Fig. 2, report the relationships for spouses working in different economic sectors and spouses with different levels of education, using the WFH index that nets out the effect of internet access at home. The correlations remain positive (with estimated coefficients of 0.10 and 0.12 , respectively) and statically significant.

Our analysis focuses on couples, but the presence of other household members can affect the intra-household consumption-smoothing possibilities. To examine this, we calculate the correlation between the average WFH index of spouses and the average WFH index of other household members aged 15-60 (other than their children) who are nonessential workers. ${ }^{19} \mathrm{We}$ find that the correlation is positive and statistically significant, with an estimated coefficient of 0.67 , indicating that the exposure to labor market risks during the pandemic is likely to be positively correlated not just for spouses, but between spouses and other household members participating in the labor market. $^{20}$

\subsection{Other consumption-smoothing strategies}

In this section, we describe the empirical association between access to other formal and informal mechanisms of consumption smoothing and the possibility of telecommuting, as a measure of exposure to the shock. Access to formal credit is low in Mexico, even compared with other Latin American countries. ${ }^{21}$ Table 8, Panel A shows the use of formal and informal mechanisms of consumption smoothing for individuals in the sample of families in which both spouses are employed in nonessential jobs. Of the

\footnotetext{
19 9\% of couples included in the analysis live with extended family members (relatives other than their children) who satisfy these conditions. To calculate the correlation we consider all couples living with extended family members and the WFH index that includes the component of internet access at home, as in Fig. 2A.

${ }^{20}$ We also calculated the intra-household correlation of WFH indexes when the husband is the only member of the couple that works (in a nonessential job). In this case, the positive association between the WFH index of the husband and the average WFH index of other household members who are employed in nonessential jobs is 0.37 . This analysis is beyond the scope of the paper but provides additional evidence on the positive intra-household correlation of the exposure to the pandemic shock.

21 According to the Global Findex database 2017, in Mexico only 5.15\% and $16.09 \%$ of households in the lower $40 \%$ and the upper $60 \%$ of the income distribution borrowed from financial institutions, respectively. These percentages are below the averages for the entire Latin America and the Caribbean region (12.41\% and $27.15 \%$, respectively) and OECD countries (64.21\% and $45.27 \%$, respectively).
} 
Table 8 Formal and informal consumption smoothing instruments. Couples in which both partners are nonessential workers

Panel A: Use of Formal and Informal Instruments

\begin{tabular}{lrrr}
\hline & All & Poor & Non-poor \\
\hline Receives Donations & $10.9 \%$ & $11.5 \%$ & $10.6 \%$ \\
Receives Remittances & $1.9 \%$ & $1.4 \%$ & $2.2 \%$ \\
Receives Private Transfers & $26.2 \%$ & $27.7 \%$ & $25.5 \%$ \\
At least one Informal Instrument & $33.5 \%$ & $35.7 \%$ & $32.5 \%$ \\
Pays using Credit Card & $18.8 \%$ & $9.6 \%$ & $22.8 \%$ \\
Informal Instruments as \% of Household Income & $8.0 \%$ & $11.1 \%$ & $6.7 \%$ \\
Credit Card Payments as \% of Household Income & $5.2 \%$ & $3.3 \%$ & $6.0 \%$ \\
\end{tabular}

Panel B: Family WFH index according to Instrument Use (Yes/No)

\begin{tabular}{|c|c|c|c|c|c|c|}
\hline & \multicolumn{2}{|c|}{ Min WFH } & \multicolumn{2}{|c|}{ Max WFH } & \multicolumn{2}{|c|}{ Avg WFH } \\
\hline & Yes & No & Yes & No & Yes & No \\
\hline Receives Donations & -0.27 & -0.12 & 0.67 & 0.87 & 0.20 & 0.37 \\
\hline Receives Remittances & -0.31 & -0.14 & 0.66 & 0.85 & 0.18 & 0.36 \\
\hline Receives Private Transfers & -0.18 & -0.13 & 0.76 & 0.88 & 0.29 & 0.38 \\
\hline At least one Informal Instrument & -0.20 & -0.11 & 0.73 & 0.90 & 0.26 & 0.40 \\
\hline Pays using Credit Card & 0.45 & -0.28 & 1.41 & 0.71 & 0.93 & 0.22 \\
\hline
\end{tabular}

Authors' calculations using data from ENIGH (2018) and PIAAC (2017)

informal sources, for the period of reference, $26.2 \%$ of households in the sample received private transfers, $10.9 \%$ received donations, and $1.9 \%$ received remittances. The percentages of poor families receiving private transfers and donations are larger than the percentages of non-poor households receiving them, but the differences are small. Approximately one-third of households in the sample reported having received money from at least one informal source, and on average, informal instruments represent $11.1 \%$ of poor households' income and $6.7 \%$ of non-poor households' income. We use data on credit cards payments as a proxy for access to formal credit instruments. ${ }^{22}$ In the period of reference, $18.8 \%$ of the households have made payments using credit cards, and nonpoor households were 2.4 times more likely to use them than poor households. Credit card payments, as a percentage of households' income, is only $5.2 \%$.

Table 8, Panel B shows how access to different consumption smoothing instruments interacts with the possibility of working from home. We present three measures of WFH at the household level: the minimum, maximum, and average, calculated by considering (in each case) the individual indexes of each spouse. Independent of the measure for the WFH index used, families reporting the use of informal instruments have lower telecommuting possibilities, on average. The opposite pattern is found for formal instruments: Households that report making payments with credit cards have, on average, higher chances of working from home. Figure 3 contains binned scatter plots, with 100 equal-sized bins for the WFH index of the household (x-axis variable), considering the

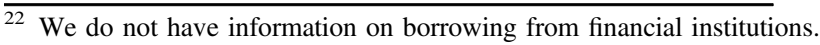



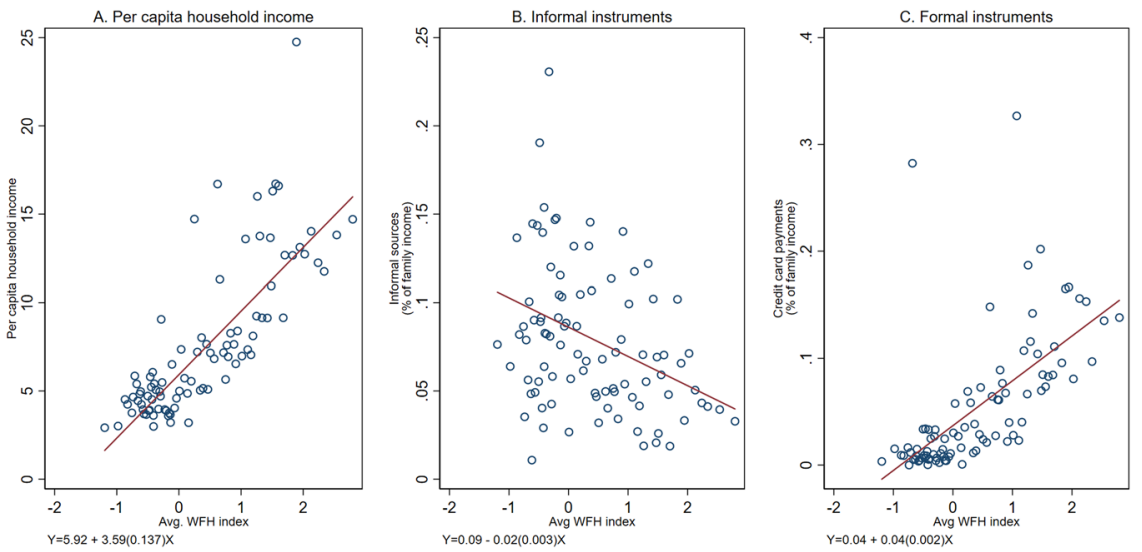

Fig. 3 Per capita household income, consumption smoothing instruments, and (average) spouses' WFH index. The minimum and maximum values of the average WFH index are -1.29 and 2.80. Authors' calculations based on data from ENIGH (2018) and PIAAC (2017)

average WFH for the spouses. The y-axis variables are per capita household income and use of informal insurance instruments (private transfers, donations, or remittances) and credit card payments as percentages of household income. A higher household WFH index is (statically significantly) associated with a higher per capita household income, a lower use of informal instruments as a percentage of household income, and a higher use of credit card payments as a percentage of household income. ${ }^{23}$

Poor households exhibit higher exposure to job market risk during the pandemic (due to their lower average WFH) and are more likely to rely on informal sources of credit than non-poor households. Moreover, if households belonging to the same informal insurance networks share a high degree of correlation in their possibilities of working from home, this will further limit the use of informal insurance mechanisms. Although the data do not allow us to identify households' social networks, we use the 2015 Intercensal Survey to explore the relationship between spouses' average WFH index and the average WFH index in the municipality where a couple lives and where we expect a significant fraction of its social network to be located. ${ }^{24}$ Figure 4A shows that couples with a low work-from-home possibility tend to live in municipalities where the average WFH index is also low (the correlation is positive and statistically significant).

This exercise builds on previous evidence consistent with extended families in the village of residence working as a source of informal insurance and resource sharing in rural villages in Mexico (Angelucci et al., 2009; Angelucci et al., 2010). While our data do not allow us to examine this relationship at the village level (smaller geographic

\footnotetext{
${ }^{23}$ In the interest of brevity, plots using alternative measures of WFH at the household level - minimum and maximum - are not reported, but the same patterns also hold for those alternative measures.

24 In the ENIGH, we calculate the average WFH index in each 2-digit occupation for men and women separately and we match the information to the Intercensal Survey of 2015 which is representative at the municipality level. Using the Intercensal Survey, we calculate the average WFH index in each municipality using the sample of all nonessential workers aged 15-60. Then, we identify couples aged 15-60 where both partners are nonessential workers and calculate the average of spouses' WFH indexes.
} 

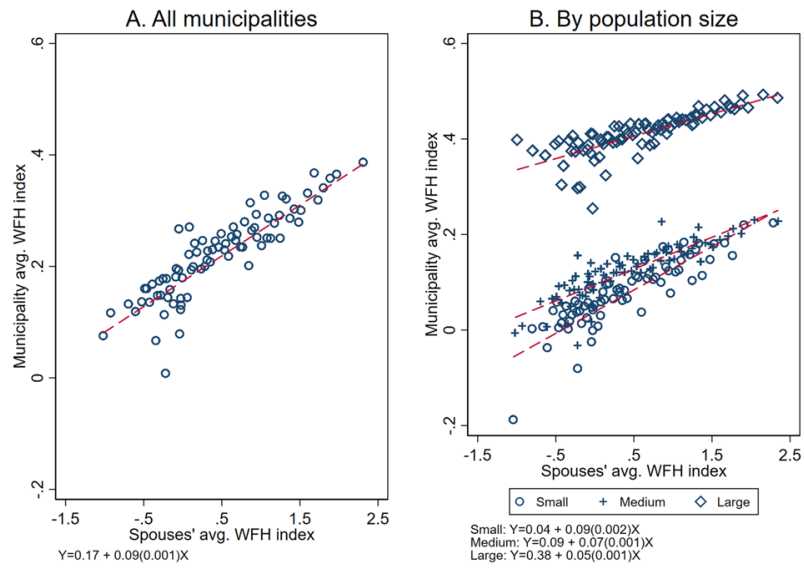

Fig. 4 Relationship between (average) municipalities' WFH index and (average) spouses' WFH index. The small municipalities category includes those with less than 2500 inhabitants; medium municipalities include those between 2,500 and 99,999 inhabitants; large municipalities comprise those with 100,000 or more inhabitants. The minimum and maximum values of the WFH index are -0.19 and 0.49 (average of the municipality) and -1.05 and 2.35. Authors' calculations based on data from ENIGH (2018), PIAAC (2017), and Intercensal Survey (2015)

units than municipalities), the average WFH index of a municipality may be thought as a better approximation of the WFH value of a household's social network when the population size of a specific municipality is small. Figure 4B shows that the positive association reported before appears in municipalities of different population size, and the correlation is stronger in smaller municipalities. Our results suggest that during the pandemic couples with higher exposure to job market risk are likely to face restrictions in their possibilities of smoothing consumption by relying on other non-essential workers in their social networks. ${ }^{25}$ Poorer households and households living in poorer villages (Angelucci et al., 2009) are expected to rely more heavily on informal sources of insurance, such as family networks. However, our analysis shows that the use of this consumption smoothing mechanism is likely to be restricted during the pandemic. ${ }^{26}$

\section{Conclusions}

The large decline in economic activity associated with the global shock imposes a constraint on intra-household consumption smoothing through adjustments in the

\footnotetext{
25 Testing for the relative importance of relying on social networks or intra-household adjustments in labor supply as consumption smoothing mechanisms is beyond the scope of the paper. The ex post efficacy of these two types of mechanisms is likely to depend on the distribution of the shock across family members and members of their social networks. Our analysis indicates that the scope for these two types of mechanisms to work is likely to be limited during the pandemic.

${ }^{26}$ Our measure of exposure to labor market risk is based on WFH indexes for non-essential workers. Social networks for couples in our sample can include persons working in nonessential or essential jobs. Considering that the average share of nonessential workers across municipalities is close to $50 \%$ and reaches $90 \%$ in some municipalities, non-essential workers are likely to be a significant fraction of the social networks of the individuals in the sample.
} 
labor supply for many individuals around the world. We have examined an additional restriction because of the positive correlation of the intensity of shocks at the household level, which limits the feasibility of intra-family risk-sharing. We believe that our analysis sheds light on an important issue: The existing intra-household occupational distribution and correlation of exposure to the crisis (measured by the possibility of telecommuting) will affect the extent to which current intra-household arrangements for consumption smoothing can work during the Covid-19 pandemic. Moreover, our results speak to the importance of studying how the prospects for working from home for individuals or households that belong to the same informal insurance network are correlated to better understand the effects of the pandemic on the insurance mechanisms that prevail in developing countries.

There are other factors that can be affecting the intra-family strategies during the pandemic. Spouses can change their extensive margin of labor supply ${ }^{27}$ and other household members can adjust their intensive or extensive margins. Our data for Mexico shows that in $45 \%$ of couples only the husband works (as opposed to $2 \%$ of the families in which only the wife works), which implies that extensive margin adjustments in couples' labor supply can almost exclusively operate if women outside the labor force enter in the labor market. Increased childcare needs related to school closings are expected to limit this mechanism. Spouses' labor supply can also be affected by the direct impact of the pandemic on health. Different types of jobs may imply heterogeneous exposure to the disease which may affect workers' physical ability to perform their tasks. Moreover, due to physical proximity, the negative Covid-19 health shock (and its impact on individual's ability to work) is likely to be positively correlated at the household level. Finally, the drop in demand may result in reductions in employment even for workers having the possibility of working from home. If anything, all these factors are likely to amplify the negative impact of the pandemic on the efficacy of intra-household risk-sharing strategies.

Our findings suggest that the current crisis is likely to increase the probability that poor households' income will fall below a certain critical threshold. In this context, in which the role of the family in smoothing consumption fluctuations is expected to be narrow, the negative impact of the pandemic on household incomes could be cushioned by government transfers and labor protection mechanisms. These factors, however, can be expected to be weak considering the scarce resources that Mexico has allocated to finance crisis-relief measures and the large share of informal workers in the country. As a result, income inequality in Mexico is likely to increase.

The current crisis is expected to have long-run labor market consequences. Short-term unemployment is likely to have an impact on labor market outcomes due to its effect on experience, which is an important determinant of wages and future employment prospects (Jarosch, 2015; Alon et al., 2020a). In addition, if containing the spread of the virus requires a "new normal", with social distancing policies in place for a long period of time, households may have incentives to adjust their occupational choices internalizing the new dimension of exposure to labor market risks. These adjustments, however, are expected to be costly and to have nontrivial distributional effects.

27 The mechanism that examines changes in the extensive margin of other household members' labor supply is referred to in the literature as the "added worker effect" (Lundberg, 1985). 


\section{Compliance with ethical standards}

Conflict of interest The authors declare that they have no conflict of interest.

Publisher's note Springer Nature remains neutral with regard to jurisdictional claims in published maps and institutional affiliations.

\section{References}

Acemoglu, D., \& Autor, D. (2011). Skills, tasks and technologies: Implications for employment and earnings. In Handbook of Labor Economics, vol. 4B, chap. 12, 1043-1171. Elsevier. https://EconPapers.repec. org/RePEc:eee:labchp:5-12.

Adams-Prassl, A., Boneva, T., \& Golin, M. (2020). Inequality in the Impact of the Coronavirus Shock: Evidence from Real Time Surveys. Working Paper WP2018, Cambridge-INET. https://www.inet. econ.cam.ac.uk/research-papers/wp-abstracts?wp=2018.

Almeida, R. K., Fernandes, A. M., \& Viollaz, M. (2020). Software adoption, employment composition, and the skill content of occupations in chilean firms. Journal of Development Studies, 56, 169-185.

Alon, T., Doepke, M., Olmstead-Rumsey, J., \& Tertilt, M. (2020a). The impact of Covid-19 on gender equality. Covid Economics, 4, 62-85.

Alon, T., Doepke, M., Olmstead-Rumsey, J., \& Tertilt, M. (2020b). This time it's different: The role of women's employment in a pandemic recession. Unpublished manuscript. Department of Economics, Northwestern University.

Ambrosius, C., \& Cuecuecha, A. (2013). Are remittances a substitute for credit? carrying the financial burden of health shocks in national and transnational households. World Development, 46, $143-152$.

Ambrosius, C., \& Cuecuecha, A. (2016). Remittances and the use of formal and informal financial services. World Development, 77, $80-98$.

Angelucci, M., \& De Giorgi, G. (2009). Indirect effects of an aid program: how do cash transfers affect ineligibles' consumption? American Economic Review, 99, 486-508.

Angelucci, M., De Giorgi, G., Rangel, M., \& Rasul, I. (2009). Village economies and the structure of extended family networks. The B.E. Journal of Economic Analysis \& Policy, 9, 1-46.

Angelucci, M., De Giorgi, G., Rangel, M. A., \& Rasul, I. (2010). Family networks and school enrolment: Evidence from a randomized social experiment. Journal of Public Economics, 94, 197 - 221.

Basu, K. (2006). Gender and say: a model of household behaviour with endogenously determined balance of power. The Economic Journal, 116, 558-580.

Beland, L.-P., Brodeur, A., \& Wright, T. (2020). COVID-19, stay-at-home orders and employment: Evidence from CPS Data. IZA Discussion Papers 13282, Institute of Labor Economics (IZA). https:// ideas.repec.org/p/iza/izadps/dp13282.html.

Del Boca, D., Oggero, N., Profeta, P., \& Rossi, M. (2020). Women's and men's work, housework and childcare, before and during COVID-19. Review of Economics of the Household, 18, 1001-1017.

Boeri, T., Caiumi, A., \& Paccagnella, M. (2020). Mitigating the work-safety trade-off. Covid Economics, 2, 60-66.

Bruhn, M., \& Love, I. (2014). The real impact of improved access to finance: Evidence from Mexico. The Journal of Finance, 69, 1347-1376.

Delaporte, I., \& Peña, W. (2020). Working from home under Covid-19: Who is affected? Evidence from Latin American and Caribbean countries. Covid Economics, 14, 200-229.

Dercon, S. (2002). Income risk, coping strategies, and safety nets. The World Bank Research Observer, 17, $141-166$.

Dingel, J. I., \& Neiman, B. (2020). How many jobs can be done at home? Journal of Public Economics, $189,104235$.

Doepke, M., \& Tertilt, M. (2016). Families in macroeconomics. In Taylor, J. B. \& Uhlig, H. (eds.) Handbook of macroeconomics, vol. 2. Elsevier. 1789-1891. https://ideas.repec.org/h/eee/macchp/v21789.html.

Fernández, R., Fogli, A., \& Olivetti, C. (2004). Mothers and sons: Preference formation and female labor force dynamics. The Quarterly Journal of Economics, 119, 1249-1299.

Garrote Sanchez, D., Gomez Parra, N., Ozden, C., \& Rijkers, B. (2020a). Which Jobs Are Most Vulnerable to COVID-19? What an Analysis of the European Union Reveals. World Bank Other Operational Studies. The World Bank. https://ideas.repec.org/p/wbk/wboper/33737.html. 
Garrote Sanchez, D., Gomez Parra, N., Ozden, C., Rijkers, B., Viollaz, M., \& Winkler, H. (2020b). Who on Earth Can Work from Home? Policy Research Working Paper Series 9347, The World Bank. https://ideas.repec.org/p/wbk/wbrwps/9347.html.

Gottlieb, C., Grobovsek, J., \& Poschke, M. (2020a). Working from home across countries. Covid Economics, 8, 71-91.

Gottlieb, C., Grobovsek, J., Poschke, M., \& Saltiel, F. (2020b). Lockdown accounting. Covid Economics, $31,103-129$.

Hale, T., Webster, S., Petherick, A., Phillips, T., \& Kira, B. (2020). Oxford Covid-19 government response tracker, blavatnik school of government. Data use policy: Creative Commons Attribution CC BY standard.

Hatayama, M., Viollaz, M., \& Winkler, H. (2020). Jobs' amenability to working from home: Evidence from skills surveys for 53 countries. Policy Research Working Paper 9241, The World Bank . https:// openknowledge.worldbank.org/handle/10986/33753.

Heggeness, M. L. (2020). Estimating the immediate impact of the COVID-19 shock on parental attachment to the labor market and the double bind of mothers. Review of Economics of the Household, 18, 1053-1078.

Inglehart, R., Haerpfer, C., Moreno, A., Welzel, C., Kizilova, K., Diez-Medrano, J., Lagos, M., Norris, P., Ponarin, E., \& Puranen, B. et al. (eds.) (2014). World Values Survey: Round Six - Country-Pooled Datafile. Version: http://www.worldvaluessurvey.org/WVSDocumentationWV6.jsp. Madrid: JD Systems Institute.

Jarosch, G. (2015). Searching for job security and the consequences of job loss. Unpublished manuscript. Jayachandran, S. (2020). Social norms as a barrier to women's employment in developing countries. Working Paper 27449, National Bureau of Economic Research. http://www.nber.org/papers/w27449.

Juhn, C., \& Potter, S. M. (2007). Is there still an added-worker effect? Staff Reports 310, Federal Reserve Bank of New York. https://ideas.repec.org/p/fip/fednsr/310.html.

Lekfuangfu, W. N., Piyapromdee, S., Porapakkarm, P., \& Wasi, N. (2020). On Covid-19: New implications of job task requirements and spouse's occupational sorting. Covid Economics, 12, 87-103.

Lewandowski, P., Park, A., Hardy, W., \& Yang, D. (2019). Technology, skills, and globalization: explaining international differences in routine and nonroutine work using survey data. IBS Working Papers 04/2019, Instytut Badan Strukturalnych. https://ideas.repec.org/p/ibt/wpaper/wp042019.html.

Lundberg, S. (1985). The added worker effect. Journal of Labor Economics, 3, 11-37.

Malkov, E. (2020). Nature of work and distribution of risk: Evidence from occupational sorting, skills, and tasks. Covid Economics, 34, 15-49.

Mongey, S., Pilossoph, L., \& Weinberg, A. (2020). Which workers bear the burden of social distancing policies? NBER Working Papers 27085, National Bureau of Economic Research, Inc. https://ideas. repec.org/p/nbr/nberwo/27085.html.

Parker, S., \& Skoufias, E. (2004). The added worker effect over the business cycle: evidence from urban mexico. Applied Economics Letters, 11, 625-630.

Rosenzweig, M. R. (1988). Risk, implicit contracts and the family in rural areas of low-income countries. The Economic Journal, 98, 1148-1170.

Rosenzweig, M. R., \& Stark, O. (1989). Consumption smoothing, migration, and marriage: evidence from rural india. Journal of Political Economy, 97, 905-926.

Saltiel, F. (2020). Who can work from home in developing countries? Covid Economics, 7, 104-118.

Sevilla, A., \& Smith, S. (2020). Baby steps: the gender division of childcare during the COVID-19 pandemic. IZA Discussion Papers 13302, Institute of Labor Economics (IZA).

Skoufias, E., \& Parker, S. (2006). Job loss and family adjustments in work and schooling during the Mexican peso crisis. Journal of Population Economics, 19, 163-181.

World Bank (2020). The economy in the Time of Covid-19. The World Bank. https://doi.org/10.1596/9781-4648-1570-6. 